\title{
Survey of motivation for use of voluntary counseling and testing services for HIV in a high risk area of Shenyang, China Ling Zhou ${ }^{\dagger 1}$, Junqiao Guo ${ }^{\dagger 2}$, Lijuan Fan ${ }^{\dagger 3}$, Jing Tian ${ }^{\dagger 4}$ and Baosen Zhou*1
}

Address: ${ }^{1}$ Department of Epidemiology, School of Public Health, China Medical University, Shenyang, PR China, ${ }^{2}$ Liaoning Provincial Center for Disease Control and Prevention, Shenyang, PR China, ${ }^{3}$ Heping County Center for Disease Control and Prevention, Shenyang, PR China and ${ }^{4}$ Heping County board of health, Shenyang, PR China

Email: Ling Zhou - zhouling.0910@163.com; Junqiao Guo - guojunqiao@Incdc.com; Lijuan Fan - flj_sy@163.com; Jing Tian - tianj@sina.com; Baosen Zhou* - bszhou@mail.cmu.edu.cn

* Corresponding author †Equal contributors

Published: 5 February 2009

BMC Health Services Research 2009, 9:23 doi:10.1186/1472-6963-9-23

This article is available from: http://www.biomedcentral.com/1472-6963/9/23

(C) 2009 Zhou et al; licensee BioMed Central Ltd.

This is an Open Access article distributed under the terms of the Creative Commons Attribution License (http://creativecommons.org/licenses/by/2.0), which permits unrestricted use, distribution, and reproduction in any medium, provided the original work is properly cited.
Received: II July 2008

Accepted: 5 February 2009

\begin{abstract}
Background: HIV voluntary counseling and testing (VCT) is considered an effective prevention method of HIV infection. In order to understand the VCT environment and enhance the effective delivery of VCT services in a country, an accurate assessment of the current status of VCT services is very important.
\end{abstract}

Methods: From July 2006 to June 2007, we conducted a cross-sectional survey using a face to face interview among 2676 VCT clients from a high risk area in Shenyang city, China.

Results: The major demographic characteristics among 2,676 VCT clients were: $41.1 \%$ were in the age range 20 to 30 years; $73.1 \%$ were males; and $67.1 \%$ had attained the level of junior high school education. The primary information source for VCT services was mass media like television (TV) and newspaper in $88.9 \% .34 .3 \%$ were afraid of the result of infection which was the main barrier to accept VCT services among 540 participants answering the question. $75.2 \%$ were motivated by recently acquired knowledge about HIV. $47.9 \%$ had 3 or more male sex partners, $62.3 \%$ had used condoms sometimes, and $14.5 \%$ had been infected with a STD. $2.8 \%$ of the participants identified themselves as men who have sex with men (MSM). The main demographic characteristics of MSM did not differ from the total group of participants except with respect to age: $63.5 \%$ reported having one male sex partner in the preceding 12 months, $44.6 \%$ reported never using condoms in the preceding 12 months, and only $2.7 \%$ reported a history of sexually transmitted disease.

Conclusion: Public education offered by health workers in hospitals, private clinics and other medical institutions needs to be strengthened. Given the results from this study, we recommend: (I) making VCT a routine part of health services, especially in areas where many high-risk individuals live; (2) improving the information sources and increasing the understanding of HIV and HIV-infected individuals; (3) enhancing international collaboration in strategic planning, technical assistance, and protocols to translate policy into effective action; (4) supporting Chinese nongovernment organizations (NGOs) in playing a significant role in the battle against AIDS. 


\section{Background}

There are some 37.8 million people living with HIV (human immunodeficiency virus)/AIDS (acquired immunodeficiency syndrome) globally of which about 7.4 million live in Asia. Around one million HIV positive people live in China, according to official estimates [1]. Currently, China has the second highest number of people living with HIV/AIDS (PLHA) in Asia and is ranked 14th in the world [2]. The national estimate of the number of PLHA at the end of 2003 was 840,000 (650,000$1,020,000)$, with a prevalence rate in the general population of $0.07 \%(0.05 \%-0.08 \%)$. The UN estimates that China may have 10 million people infected with the HIV virus by 2010 unless effective action is taken in 2002 [3].

Shenyang city is the capital of Liaoning Province, the largest and most industrialized city in Northeast China. Xita area is located in the center of Shenyang and has communicated largely with other countries in economy and culture. Xita area occupies 0.58 square kilometers, with a total population of 23,167, of which 5893 are of the Korean ethnicity. It has a floating population of 3,600 who is temporary rural-urban labor migration. There are 207 entertainment places, such as pubs, hairdressing salons, bathing centers, massage parlors, song bars, hotel and ballrooms. Xita area has the world's second largest expatriate Korean community, after Los Angeles, USA [4]. With economic development, Xita area has become an area with high incidence of HIV/AIDS. In 2003, the Chinese government established 51 HIV comprehensive prevention and care model points countrywide. The only point in Shenyang is situated in Xita, because it harbours a substantial number of high risk populations like injecting drug users, commercial sex workers and MSM who have been identified as high populations of HIV/AIDS in China [5-7].

The number of MSM in China was estimated at between 2 to 8 million $[6,8]$, and $47,000 \mathrm{MSM}$ were estimated to be living with HIV/AIDS, accounting for $7.3 \%$ of the total number of estimated HIV cases by the end of 2004 in China [9]. Most of the known MSM population resides in the metropolitan areas. MSM can be divided into three categories: homosexual, heterosexual and bisexual. Unprotected sexual activities, including group sex, anal sex, casual sex and commercial sex are prevalent among Chinese MSM [10]. A study published in 2006 revealed that $41 \%$ Of MSM had engaged in sex with women as well as men, including married women [10]. MSM are at high risk of HIV infection and contribute to the spread of HIV to women and the general population. In addition, groups of male commercial sex workers who have sex with men only for money have appeared in many large cities.

A policy was developed to combat HIV/AIDS in China known as the "Four-free plus care": (1) free antiretroviral
(ARV) drugs to AIDS patients who are rural residents, or people with financial difficulties living in urban areas; (2) free VCT in areas where the disease is prevalent; (3) free ARV drugs to HIV infected pregnant women to prevent MTCT, and HIV testing of newborns babies; (4) free schooling for children orphaned by AIDS; and (5) care and economic assistance to the households of people living with HIV/AIDS. VCT has been described as an important intervention for HIV prevention as it may serve as an entry point for prevention and care and support for those found infected $[11,12]$. It is considered an effective method of prevention of HIV infection, as well as improves the quality of care and assistance to HIV infections [13]. By the end of 2005, there were 2,850 free VCT clinics throughout the country [9].

In order to enhance the effective delivery of VCT services in a country, an accurate assessment of the current status is very important. A study by Weiser et al. in Botswana among people who were never tested for HIV, showed that the major reason for not testing was fear of a positive HIV test result [14]. Jereni et al. surveyed clients of VCT in Malawi to assess their motivations for HIV testing. They found that obtaining knowledge about HIV recently was the main motivation for seeking VCT [13]. The same result was found by Sherr et al. [15]. Perceived risk of HIV infection had a major influence on VCT readiness among young people in an urban population in Zambia [16]. Low perceived risk for HIV infection is major reason for ignoring HIV testing and counseling in some areas $[17,18]$.

Information sources, barriers and motivations for seeking VCT services vary from place to place and could vary from time to time. The aims of this study were: (1) to understand the demographic and behavioral characteristics of the individuals seeking VCT services in Xita area; (2) to describe the demographic and behavioral characteristics of MSM among those seeking VCT services; (3) to find effective means of communication and service, and improve the effectiveness of VCT system, through the study of information sources, barriers and motivations for seeking VCT service.

\section{Methods}

This was a cross sectional study utilizing a standardized interview questionnaire designed for the survey to assess information sources, barriers, and motivations of VCT.

\section{Participants}

We selected Xita area which is one of 51 communitybased HIV/AIDS comprehensive care pilot centers in regions with the greatest number of HIV/AIDS cases. The participants were the VCT clients from July 2006 to June 2007. The Chinese government owned the Korean National Hospital and Maternity and Child Care Centers 
provided VCT services. Providing VCT service is only a partial function of the two facilities. The minimum age to take VCT without parental consent is 18 years.

Inclusion criteria in the study were: (1) the age range 20 to 65 years; (2) willingness to participate in the interview after detailed explanation by interviewers. Informed consent was obtained before the interview. MSM were defined as men had sex with men in the past one year. We invited 7517 VCT clients who were in the age range 20 to 65 years to participate in the study, $35.6 \%$ agreed to been interviewed.

\section{Data collection}

The study instrument included a 15-min questionnaire, which was designed for the survey and administered faceto-face to all participants. The interview points were the department providing VCT services of the Korean National Hospital and Maternity and Child Care Centers. The interview occurred before testing. The questionnaire included demographic and behavioral characteristics, information sources, barriers, and motivations of VCT. MSM and other participants were interviewed using the same questionnaire. The health workers who provided VCT services were trained to take the interview. The questions about barriers explored why the participants had never been tested before they presented at the VCT clinic.

\section{Data analysis}

Quantitative data were entered into and analyzed using Epi Info software. We also performed chi-square test to assess any differences in responses between males and females, MSM and the general population. A p value of < 0.05 was considered statistically significant.

\section{Ethical issues}

This study was approved by the Ethics Committee of China Medical University. The study was done under the full knowledge and consent by participants, who were assured of the security of the information. Written, informed consent was received from all study participants before the HIV testing. All study participants received a soft drink during the interview and gifts after the interview. The gifts were HIV prevention handbooks, nail-clippers and a 40 Yuan coupon for free testing and counseling services at designated facilities.

\section{Results}

\section{The demographic characteristics of participants}

Socio-demographic characteristics are presented in Table 1 . There were 2,676 participants in the survey. Of the participants seeking VCT during the study period in Xita, $41.1 \%$ were in the age range of 20 to 30 years, and the majority $(67.1 \%)$ had attained the level of junior high school. $73.1 \%$ were males while $26.9 \%$ were females. Most were married (59.3\%) followed by single partici-

Table I: Demographic characteristics of the participants

\begin{tabular}{|c|c|c|c|c|c|}
\hline \multicolumn{2}{|c|}{ Characteristic } & \multicolumn{2}{|c|}{ Total } & \multicolumn{2}{|c|}{ MSM a } \\
\hline & & Number & $\%$ & Number & $\%$ \\
\hline \multirow[t]{4}{*}{ Age } & $20-30$ & 1099 & $41.1 \%$ & 21 & $28.4 \%$ \\
\hline & $31-40$ & 1067 & $39.9 \%$ & 36 & $48.6 \%$ \\
\hline & $4 I-50$ & 403 & $15.1 \%$ & 12 & $16.2 \%$ \\
\hline & $51-65$ & 107 & $4.0 \%$ & 5 & $6.8 \%$ \\
\hline \multirow[t]{2}{*}{ Sex } & Male & 1957 & $73.1 \%$ & 74 & $100 \%$ \\
\hline & Female & 719 & $26.9 \%$ & - & - \\
\hline \multirow[t]{3}{*}{ Ethnicity } & Han & 2219 & $82.9 \%$ & 64 & $86.5 \%$ \\
\hline & Korean & 432 & $16.1 \%$ & 7 & $9.5 \%$ \\
\hline & Other & 25 & $0.9 \%$ & 3 & $4.1 \%$ \\
\hline \multirow[t]{4}{*}{ Education Level } & Elementary school/none & 53 & $2.0 \%$ & 2 & $2.7 \%$ \\
\hline & Junior high school & 1795 & 67.1 & 45 & $60.8 \%$ \\
\hline & Senior high school & 602 & $22.5 \%$ & 19 & $25.7 \%$ \\
\hline & College & 226 & $8.4 \%$ & 8 & $10.8 \%$ \\
\hline \multirow[t]{3}{*}{ Marital Status } & Single & 701 & $26.2 \%$ & 12 & $16.2 \%$ \\
\hline & Married & 1586 & $59.3 \%$ & 51 & $68.9 \%$ \\
\hline & Separated/divorced & 389 & $14.5 \%$ & 11 & $14.9 \%$ \\
\hline \multirow[t]{3}{*}{ Sexual self-identity } & Homosexual & 0 & 0 & 0 & 0 \\
\hline & Heterosexual & 2674 & $99.93 \%$ & 72 & $97.3 \%$ \\
\hline & Bisexual & 2 & $0.07 \%$ & 2 & $2.7 \%$ \\
\hline \multicolumn{2}{|c|}{ Total } & 2676 & $100 \%$ & 74 & $100 \%$ \\
\hline
\end{tabular}

a MSM were extracted from 'total' and 'males' 
Table 2: Information sources of the participants

\begin{tabular}{|c|c|c|c|c|}
\hline Source & Total (\%) & Males (\%) & Females (\%) & MSM a $(\%)$ \\
\hline Media-TV, newspaper and radio & $2380(88.9)$ & $1733(88.6)$ & $647(90.0)$ & $64(86.5)$ \\
\hline Public education by community or Red Cross & $1134(42.4)$ & $829(42.4)$ & $305(42.4)^{*}$ & $29(39.2)$ \\
\hline Recommendation offered by health workers & $315(11.8)$ & $230(11.8)$ & $85(11.8)^{*}$ & $13(17.6)$ \\
\hline Friends/family & $722(27.0)$ & $533(27.2)$ & $189(26.3)$ & $19(25.7)$ \\
\hline Internet & $1030(38.5)$ & $744(38.0)$ & $286(39.8)$ & $33(44.6)$ \\
\hline Others & $494(18.5)$ & $378(19.3)$ & $116(16.1)$ & $15(20.3)$ \\
\hline
\end{tabular}

a MSM were extracted from 'total' and 'males'

* Significantly different between males and females $(p<0.05)$

pants (26.2\%) and divorced participants (14.5\%). The majority was of the Han ethnicity (82.9\%).

\section{Information sources of participants}

Information sources, stratified by gender and sexual orientation are presented in Table 2. There were 2,623 $(98.0 \%)$ participants answering this question in Xita. $88.9 \%$ acquired the VCT services information from media reported as the most common source, such as TV, newspaper and radio. Females were more likely to acquire information from the public education by community or Red Cross and the recommendation offered by health workers than males, $\mathrm{p}<0.05$.

\section{Barriers to VCT}

Participants indicated whether any of the listed factors served as a barrier for them (Table 3 ). They could agree with multiple possible responses. Of the 540 participants answering the question in Xita, 185 participants were afraid of the result of infection which was the main barrier to accept VCT service. There was no difference in barriers to VCT between males and females.

\section{Motivations for seeking VCT services}

Two thousand and eighty-five (77.9\%) participants answered this question (Table 4). Of these, 2,013 participants $(75.2 \%)$ considered that recent knowledge about HIV was the main motivation. Males and females did not differ in the various motivations except recent knowledge about HIV.

Table 3: Barriers to VCT

\section{Behavioral characteristics of participants}

$47.9 \%$ had 3 or more sex partners, $62.3 \%$ participants had used condoms sometimes, and $14.5 \%$ had been infected with a STD.

\section{The demographic characteristics, behavioral characteristics, information sources, barriers and motivations for MSM who sought VCT services}

Seventy-four persons were MSM in the survey. The main demographic characteristics of MSM did not differ from the entire participants, except for age (Table 1). The majority $(48.6 \%)$ were in the age range 31 to 40 years. Forty-seven $(63.5 \%)$ reported having one male sex partner in the preceding 12 months (Table 5). A total of 33 (44.6\%) participants reported never using condoms in the preceding 12 months and only two (2.7\%) reported a history of a sexually transmitted disease (STD).

There were no difference between MSM and the whole participants in the major information sources and motivations. The most commonly identified barrier for the whole sample was fear of the test result, whereas the most common barrier for MSM was "other".

\section{Discussion}

To our knowledge, this is the first study about information, barriers and motivations regarding free VCT in an area with a relatively high prevalence of HIV in China. These findings are useful in the development of more effective VCT services and intervention and prevention programmes in China.

\begin{tabular}{|c|c|c|c|c|}
\hline Barrier & Total (\%) & Males (\%) & Females (\%) & MSM a (\%) \\
\hline Fear of positive test result & $185(6.9)$ & 147(7.5) & $38(5.3)$ & $4(5.4)$ \\
\hline Stigma/Discrimination on HIVIAIDS & $34(1.3)$ & $19(1.0)$ & $15(2.1)$ & $\mathrm{I}(\mathrm{I} .4)$ \\
\hline Fear of losing job, family or friends & $82(3.1)$ & $62(3.2)$ & $20(2.8)$ & $4(5.4)$ \\
\hline Fear of hospital & $56(2.1)$ & $43(2.2)$ & $13(1.8)$ & $2(2.7)$ \\
\hline Worried someone would find out about test result & $\mathrm{I}(0)$ & $0(0)$ & $\mathrm{I}(0.1)$ & $0(0)$ \\
\hline Didn't have time & $56(2.1)$ & $39(2.0)$ & $17(2.4)$ & $0(0)$ \\
\hline Others & $169(6.3)$ & $122(6.2)$ & $47(6.5)$ & $8(10.8)$ \\
\hline
\end{tabular}

a MSM were extracted from 'total' and 'males' 
Table 4: Motivations for seeking VCT services

\begin{tabular}{|c|c|c|c|c|}
\hline Motivation & Total (\%) & Males (\%) & Females (\%) & MSM a (\%) \\
\hline Feeling the symptoms of HIV & $112(4.2)$ & $91(4.6)$ & $2 I(2.9)$ & $3(4.1)$ \\
\hline Perception of own high risk behavior & $31(1.2)$ & $25(1.3)$ & $6(0.8)$ & $0(0)$ \\
\hline Recently acquired knowledge about HIV & $2013(75.2)$ & $1473(75.3)$ & $540(75.1)^{*}$ & $54(73.0)$ \\
\hline Confirmatory test & $\mathrm{I}(0)$ & $\mathrm{I}(0 . \mathrm{I})$ & $0(0)$ & $0(0)$ \\
\hline Other & $157(5.9)$ & $117(6.0)$ & $40(5.6)$ & $5(6.8)$ \\
\hline
\end{tabular}

a MSM were extracted from 'total' and 'males'

* Significantly different between males and females $(p<0.05)$

We found that $41.1 \%$ of participants were in the age range 20 to 30 years and $39.9 \%$ were in the age range 31 to 40 years. We believe this could be explained by a perception that young adults may feel more at risk due to their own sexual behaviors compared to older adults. It is also possible that the young have more comprehensive information sources than older adults because they have a larger scope of activities. Conversely, it is also plausible to consider that younger individuals have a higher degree of acceptance than older ones toward unfamiliar things. Jereni et al. reported that the majority of clients seeking VCT services were in the age range 20 to 30 years, men, the level of junior high school and married [13]. Ma W et al. reported that half of the participants were in the age range 30 to 40 years [18]. In the study by Fylkesnes et al., readiness was higher in younger than older age groups, e.g. $49 \%$ in the age range 20 to 24 years versus $23 \%$ in the age range 40 to 49 years [16]. This is in concordance with our findings.

Among information sources for VCT, the most popular one was mass media such as TV, newspaper and radio. This is most likely the result of the activities of the State AIDS Working Committee that was created in 2004 to ensure effective implementation of the State Council Document Number 7. The leaders of this committee have promoted and implemented education programs. The campaigns included: creating television shows that teach people about AIDS/HIV; inviting celebrities to make public service announcements about AIDS/HIV on TV shows or in newspaper; creating teaching materials for secondary school students and posting advertisements in public spaces, such as train and subway stations [7]. The area covered by TV or newspapers is far larger than any of the other communication media. In Guizhou province, Ma W et al. reported that the decision to be tested for HIV was influenced by the people around them [18]. In Nigeria, mass media and churches were the most common sources of information on VCT [19]. We found that information obtained from professional sources was minimal, indicating an opportunity to improve health education offered by health workers in hospitals, private clinics and other medical institutions.

Among barriers to VCT, the perception of fear of a positive HIV test result was the most common reason for not being tested. In addition, no-one indicated that they felt "worried other people would be told test results without consent" was a barrier to them. The fear of discrimination represents an important barrier to testing and counseling [20,21]. A potential explanation for this inconsistency with previous studies is that different geographical regions, cultures and economic levels have different attitudes toward VCT. Another possibility is that the subjects of this investigation were voluntary, while the subjects in

Table 5: The behavioral characteristics of the participants

\begin{tabular}{|c|c|c|c|}
\hline Characteristic & & Total (\%) & $\operatorname{MSM}^{\mathrm{a}}(\%)$ \\
\hline \multirow[t]{3}{*}{ Past year condom use } & Sometimes & $1667(62.3 \%)$ & $20(27.0 \%)$ \\
\hline & Always & $354(13.2 \%)$ & $21(28.4 \%)$ \\
\hline & None & $655(24.5 \%)$ & $33(44.6 \%)$ \\
\hline \multirow[t]{3}{*}{ Number of sex partners in past year } & 1 & $256(9.6 \%)$ & $47(63.5 \%)$ \\
\hline & 2 & $1136(42.5 \%)$ & $16(21.6 \%)$ \\
\hline & $\geq 3$ & $1284(47.9 \%)$ & $\mathrm{II}(14.9 \%)$ \\
\hline \multirow[t]{2}{*}{ History of sexually transmitted disease } & Yes & $389(14.5 \%)$ & $2(2.7 \%)$ \\
\hline & No & $2287(85.5 \%)$ & $72(97.3 \%)$ \\
\hline Total & & $2676(100 \%)$ & $74(100 \%)$ \\
\hline
\end{tabular}

a MSM were extracted from 'total' and 'males' 
the literature were individuals who didn't seek VCT services.

Our study also showed that recent knowledge about HIV was the major motivation for VCT. This result was similar to a study by Jereni et al. in Malawi [13]. In a study from Zimbabwe, Morin et al. reported that individuals who perceived themselves as being at high risk of HIV infection were more likely to present at mobile HIV testing sites [22]. That was the major motivation for seeking VCT.

No one of the MSM identified himself as being homosexual. A study from the USA reported that $79.7 \%$ identified as homosexual [23]. The reason of the significant differences with our study may be that MSM in China may be ashamed and stigma of their sexual identity and therefore conceal it deliberately.

The study has certain limitations. Firstly, the questionnaire contained some sensitive questions which could have led to low response rate or information bias. Secondly, we recruited only a small number of MSM, which may not be representative of Chinese MSM. There is need for a future studies with larger sample sizes among MSM in order to validate our findings. In addition, as the sample included only those voluntarily accessing services, the results can also not be extrapolated to the general population.

\section{Conclusion}

Public education offered by health workers in hospitals, private clinics and other medical institutions needs to be strengthened. The VCT system also needs to pay attention to education about HIV and VCT. Given the results from this study, we recommend: (1) making VCT a routine part of health services, especially in areas where many highrisk individuals reside; (2) improving the information sources and increasing the understanding of HIV and HIVinfected individuals; (3) enhancing international collaboration in strategic planning, technical assistance, and protocols to make policy into effective action; (4) supporting Chinese non-government organizations (NGOs) in playing a significant role in the battle against AIDS.

\section{Competing interests}

The authors declare that they have no competing interests.

\section{Authors' contributions}

LZ performed the statistical analysis, drafted and revised the manuscript. JG conceived of the study, and participated in its design and data collection. BZ carried out the design, data analysis and interpretation. LF and JT participated in data collection. All authors read and approved the final manuscript.

\section{Acknowledgements}

The study was funded by The European Union, United Nations International Children's Fund, China International Charity's Fund and China Global Fund AIDS Program Round 5 NGO. However the views expressed are those of the authors and not necessarily the funders. The paper has benefited from valuable comments by Peng Guan from China Medical University and modification of English language by Dr Hugo De Vuyst from International Agency for Research on Cancer. We are also grateful to Rikki Graham, Ademola Ajuwon and Fiona G. Kouyoumdjian for their helpful comments that lead to an improved version of this article.

\section{References}

I. Chen P: Measures needed to strengthen strategic HIVIAIDS prevention programmes in China. Asia Pac J Public Health 2007, 19:3-7.

2. Li DM: HIVIAIDS Epidemic Situation and Response in China. [http://www.un.org.vn/who/docs/mekonghivtb/presentations/ 8blchinaepiresponse041008.ppt].

3. Manchester T: Attitudes towards HIVIAIDS in China: Research on public knowledge, attitudes and behaviour in cities and towns. [http://www.kaisernetwork.org/health cast/ uploaded files/Futures Group 09.24.02.pdf].

4. He Y: The Power of the Nation and the Social Network behind Xita's Boom. Heilongiiang National Series 2006, 03:55-58.

5. Zhu TF, Wang $\mathrm{CH}$, Lin $\mathrm{P}, \mathrm{He} \mathrm{N}$ : High risk populations and HIVI infection in China. Cell Res 2005, I 5:852-857.

6. Qian HZ, Vermund $\mathrm{SH}$, Wang N: Risk of HIVIAIDS in China: subpopulations of special importance. Sex Transm Infect 2005, 8 I:442-447.

7. Sheng L, Cao WK: HIVIAIDS epidemiology and prevention in China. Chin Med J 2008, I 2 I: I230-1236.

8. Choi KH, Liu H, Guo Y, Han L, Mandel JS, Rutherford GW: Emerging HIV-I epidemic in China in men who have sex with men. Lancet 2003, 36 I:2125-2126.

9. Ministry of Health, People's Republic of China: 2005 Update on the HIVIAIDS Epidemic and Response in China. China. 2005.

10. Liu H, Yang H, Li X, Wang N, Liu H, Wang B, Zhang L, Wang Q, Stanyon $B$ : Men who have sex with men and human immunodeficiency virus/sexually transmitted disease control in China. Sex Transm Dis 2006, 33:68-76.

II. Bunnell R, Ekwaru JP, Solberg P, Wamai N, Bikaako-Kajura W, Were W, Coutinho A, Liechty C, Madraa E, Rutherford G, Mermin J: Changes in sexual behavior and risk of HIV transmission after antiretroviral therapy and prevention interventions in rural Uganda. AIDS 2006, 20:85-92.

12. Kawichai S, Beyrer C, Khamboonruand C, Celentanod D, Natpratan C, Rungruengthanakit K, Nelsonk E: HIV incidence and risk behaviors after voluntary HIV counseling and testing(VCT) among adults aged $19-35$ years living in peri urban communities around Chiang Mai city in northern Thailand. AIDS Care 2004, I 6:21-35

13. Jereni I Bwanali H, Muula Adamson S: Availability of supplies and motivations for accessing voluntary HIV counseling and testing services in Blantyre, Malawi. BMC Health Serv Res 2008, 8: 17.

14. Weiser SD, Heisler M, Leiter K, Percy-de Korte F, Tlou S, Demonner S, Phaladze N, Banqsbrq DR, lacopino V: Routine HIV Testing in Botswana: A Population-Based Study on Attitudes, Practices, and Human Rights concerns. PLoS Med 2006, 3:e26I.

15. Sherr L, Lopman B, Kakowa M, Dube S, Chawira G, Nyamukapa C, Oberzaucher N, Cremin I, Gregson S: Voluntary counselling and testing: uptake, impact on sexual behaviour, and HIV incidence in a rural Zimbabwean cohort. AIDS 2007, 2 I:85 I-860.

16. Fylkesnes K, Siziya S: A randomized trial on acceptability of voluntary HIV counselling and testing. Trop Med Int Health 2004, 9:566-572.

17. Nakanjako D, Kamya M, Daniel K, Mayanja-Kizza H, Freers J, Whalen C, Katabira E: Acceptance of routine testing for HIV among adult patients at the medical emergency unit at a national referral hospital in Kampala, Uganda. AIDS Behav 2007, I I:753-758.

18. Ma W, Roger Detels, Feng YJ, Wu ZY, Shen LM, Li Y, Li ZZ, Chen F, Wang AM, Liu TM: Acceptance of and barriers to voluntary 
HIV counselling and testing among adults in Guizhou province, China. AIDS 2007, 21:129-135.

19. Ikechebelu IJ, Udiqwe GO, Ikechebelu N, Imoh LC: The knowledge, attitude and practice of voluntary counselling and testing (VCT) for HIVIAIDS among undergraduates in a polytechnic in southeast, Nigeria. Niger J Med 2006, 15:245-249.

20. UNAIDS: The impact of voluntary counseling and testing: a global review of the benefits and challenges. Geneva. UNAIDS; 200I.

21. Pulerwitz J, Michaelis AP, Lippman SA, Chinaglia M, Diaz J: HIVrelated stigma, service utilization, and status disclosure among truck drivers crossing the Southern borders in Brazil. AIDS Care 2008, 20:198-204.

22. Morin SF, Khumalo-Sakutukwa G, Charlebois ED, Routh J, Fritz K, Lane T, Vaki T, Fiamma A, Coates T]: Removing the barriers to knowing HIV status: same day mobile HIV testing in Zimbabwe. J Acquir Immune Defic Syndr 2006, 41:2 18-224.

23. CDC: HIV Prevalence, Unrecognized Infection, and HIV Testing Among Men Who Have Sex with Men - Five U.S. Cities, June 2004 - April 2005. JAMA 2005, 294:674-676.

\section{Pre-publication history}

The pre-publication history for this paper can be accessed here:

http://www.biomedcentral.com/1472-6963/9/23/prepub

Publish with Biomed Central and every scientist can read your work free of charge

"BioMed Central will be the most significant development for disseminating the results of biomedical research in our lifetime. "

Sir Paul Nurse, Cancer Research UK

Your research papers will be:

- available free of charge to the entire biomedical community

- peer reviewed and published immediately upon acceptance

- cited in PubMed and archived on PubMed Central

- yours - you keep the copyright 